\title{
FAIRCLOUGH, N. ANALYSING DISCOURSE. TEXTUAL ANALYSIS FOR SOCIAL RESEARCH. LONDRES: ROUTLEDGE, 2003, 269 PÁGS.
}

\section{Resenhado por: Rubens Morais}

Apresento o livro tomando por base o conceito de texto relacionado aos conceitos de gênero/discurso/estilo, uma vez que essa discussão é, por assim dizer, o cerne das questões propostas neste arcabouço esmiuçado por meio das análises dos textos que são encontradas em praticamente todos os capítulos do livro.

Não à toa o livro se chama Analysing discourse, pois, como explicitado em vários momentos, o objetivo ali é precipuamente a análise lingüística de textos, embora o autor diga que seu intento não é a análise pela análise, uma vez que a obra faz parte de um projeto científico mais amplo, sendo, desse modo, apenas uma parte dessa tarefa, digamos, social, uma vez que o 'projeto' a que se refere é a busca de uma forma de se fazer ciência no campo da pesquisa social, tomando como mote, especificamente, as mudanças na vida contemporânea, mais precisamente no capitalismo hodierno e seu impacto na vida social - tema que, segundo o autor, tem encontrado bastante espaço na área da Análise de Discurso Crítica (daqui para frente $\mathrm{ADC}$ ). $\mathrm{Ou}$, em outros termos, a obra pretende descortinar o que subjaz às mudanças numa sociedade globalizada/pós-moderna/de informação, entre outras alcunhas utilizadas pelos teóricos para se referirem a esse 'capitalismo tardio' do século XXI, e ao qual Fairclough vai se referir em seu texto.

Antes de avançar na análise de textos, Fairclough relembra o que torna crítica a análise crítica de discurso, além de resgatar conceitos que embasam a teoria a que se dedica, não nos deixando perder de vista que a ADC é baseada numa concepção de semiose como um elemento irredutível de todo o processo social material, o que nos leva a perceber a vida social como interconectada a redes de práticas de diversos tipos (econômico, político, cultural, familiar, etc.), lembrando-nos, ainda, como bem salientado 
em obras anteriores, que é o estudo crítico da dialética das práticas, sejam elas sociais ou discursivas, que permitirá que se tenha uma compreensão do que se passa no âmbito social e lingüístico. Somente desse modo se poderá perceber como um domínio está imbricado no outro; como se influenciam mutuamente, gerando, por exemplo, os 15 textos que serão tomados de empréstimo pelo autor para serem desnudados na obra em questão.

Diferentemente do que se passa em obras anteriores, nesta Fairclough preconiza a análise interdiscursiva do texto em intercâmbio com a ação/ representação/identificação, as quais representariam o que ele chama de '3 principais aspectos do sentido do texto'. Esses 'aspectos' corresponderiam, ainda, às categorias de gênero/discurso/estilo no nível das práticas sociais. Dito de outra forma, a proposta do autor é examinar o caráter interdiscursivo do texto, tomando por base a mescla de gêneros/discursos/estilos. É essa articulação que está em jogo, em síntese. O autor fala, inclusive, em 'textura' (p. 37) desses elementos em ordens de discurso, para indicar a imbricação dos elementos entre si. E, por enfatizar a forma como se dá essa ‘texturização', Fairclough não deixa dúvidas quanto à sua inclinação teórica neste novo livro, qual seja a de observar o caráter interdiscursivo de um texto - na mescla de gêneros/discursos/estilos - em vários níveis da organização textual (semântica, gramatical, lexical/p. 67).

Os textos, entendidos como partes dos eventos sociais, têm a primazia de gerarem efeitos, ao ponto de alterar nossos conhecimentos, crenças, atitudes e valores; de forma que, para o autor, não haveria muito sentido em estudar as transformações pelas quais passa a língua no novo capitalismo sem se debruçar sobre os textos: 'O mundo social é textualmente construído’, diz o autor (p. 9), o que, me parece, justifica a ênfase dada a essa instância da língua, nesse novo livro.

Por meio dos exemplos apresentados, o autor vai desenredando vários níveis de análise textual. Discute os seguintes aspectos: 1) as relações externas: estruturas sociais, práticas sociais, eventos sociais, numa relação considerada in absentia, ou paradigmática; e 2) as relações internas, in praesentia ou sintagmáticas: semântica, gramática/vocabulário/fonologia ( $\mathrm{p}$. 36), e as relações interdiscursivas que permeiam tanto as relações internas quanto as externas. Na verdade, o autor faz essa 'radiografia' da relação 
(inter)textual para, como quando fala sobre gêneros, discursos e estilos, apontar a dialogicidade, o hibridismo por meio dos quais os textos se constroem.

A seguir, deter-me-ei nos principais aspectos apontados sobre gênero/discurso/estilo, os quais, como já salientado, estão diretamente ligados à construção do texto.

O gênero está muito ligado à idéia de ação e interação lingüísticas; a uma forma de transformação. De acordo com o autor, a mudança de um gênero é parte das transformações do novo capitalismo, tema que ilustra as análises feitas na obra. Fica clara a não-existência de uma terminologia definitiva para um gênero. Mesmo os gêneros já estabelecidos - e creio que neste momento ele esteja se referindo a uma questão mais terminológica (p. 66) -, devem ser vistos com prudência, pois os gêneros estão em constante transformação, numa espécie de fluxo. A partir desse raciocínio, o autor apresenta diversas classificações de gênero, tais como genre chains, genre mixing, genre mixture, pre-genres (cap. 4), para ilustrar o que eu chamaria de 'gênero em movimento', isto é, diferentes gêneros mesclando-se, em diferentes níveis de abstração, dando existência, dessa forma, a gêneros novos. É claro que quando o autor fala dessa hibridização do gênero, ele está falando de interdiscursividade; e, embora o autor já viesse falando em 'gênero' nos trabalhos anteriores, nesse novo livro ele se detém no conceito de forma mais elaborada, explicando e mostrando como se dá essa movimentação do gênero. Vale observar, ainda, que, ao se referir à relação gênero/texto, o autor deixa claro que os gêneros estruturam textos em formatos específicos, e que, nessa propalada hibridização, um texto pode conter diversos outros gêneros.

Uma das idéias de discurso defendida pelo autor é o discurso como uma forma particular de representar aspectos do mundo (físico, social, psicológico), podendo ser 'projetivo' (p. 124), imaginário, possibilitando, inclusive, a representação de mundos possíveis, os quais trilham caminhos diversos daqueles demarcados pelo mundo que conhecemos hoje. Com isso, o autor quer dizer que os discursos transcendem representações meramente concretas e locais, pois um único discurso poderá gerar muitas representações específicas. Nos textos, por exemplo, podem-se descobrir 
diversas maneiras de representação, mas, ressalta, não poderíamos chamar cada representação de um discurso separado. $\mathrm{O}$ autor se pergunta como poderia identificar diferentes discursos em um texto, e responde a si mesmo, dizendo que isso será possível se pensarmos no discurso como representação de alguma parte do mundo e, também, como representação do mundo de uma perspectiva particular. Desse modo, imagino, é que se poderá, por exemplo, falar em discurso x, discurso y, num mesmo texto, de acordo com as representações de mundo que se encontrem nesse texto.

Assim como faz ao discorrer sobre gênero, Fairclough diz que o discurso pode ser identificado e diferenciado em diversos níveis de abstração. Seria uma espécie de fluidez textual? É bem provável que a resposta seja 'sim', considerando que, para o autor, faz muito sentido falar em 'discurso do novo espírito do capitalismo', por exemplo, ao se referir a um discurso com alto nível de abstração e que traz, em seu rastro, a articulação de vários outros discursos. É, uma vez mais, a idéia tão profícua nas ciências humanas de hoje acerca da 'hibridização' dos conceitos e do mundo.

A obra demonstra, ainda, uma preocupação com os textos no processo de constituição das identidades sociais/pessoais dos falantes nos eventos dos quais fazem parte. O estilo é visto como analiticamente distinto de, embora dialeticamente interconectado com, gêneros e discursos. $\mathrm{O}$ autor ressalta que estilos são o aspecto discursivo dos modos de ser, identidades. Diz, ainda, que quem você é passa a ser parcialmente uma questão de como você fala, escreve; o modo como se mostra; se movimenta (p. 159). Ressalta que todos esses aspectos envolvem uma interface entre corpo e língua. Dá o exemplo da construção da identidade política de Tony Blair, cuja identificação é construída desde as expressões faciais que emprega até a vestimenta de que se apropria, em suas aparições púbicas. Desse modo, acredita o autor, o que as pessoas põem nos textos é um importante indício de como se auto-identificam na 'texturização' das identidades. É nesse momento que o autor tenta mostrar a ligação que existe entre identidade social e identidade pessoal, e como essa relação pode ser investigada pela análise textual, no estudo da modalidade textual.

Da mesma forma como ocorreu com as concepções de gênero e de discurso, o estilo, que traz em seu bojo a representação das identidades, 
seja identidade social ou pessoal, também é apresentado em uma visão dialética entre o sujeito e a sociedade. Além disso, o estilo também pode ser identificado em diferentes níveis de abstração, embora, nesse caso específico, os estilos estejam relacionados às formas pelas quais as personalidades investem nas identidades sociais, que são múltiplas e multifacetadas. Dessa forma, somente uma análise textual poderia ajudar a enxergar essa construção, nos textos que buscamos analisar.

Os três tipos de significação em um texto, ação/representação/identificação, e que correspondem às categorias de gênero/discurso/estilo - que são detalhadas no livro, contam com diversas subcategorizações, que serão instrumentos úteis na análise de textos. Como diz Fairclough, não se pode simplesmente supor o papel do discurso nas práticas sociais, isso tem que ser estabelecido por meio da análise. E, como o título da obra já diz, o principal objetivo ali é a análise de textos. Entretanto, o autor precisa buscar categorias para fazer esse trabalho. Desse modo, deixa claro, em vários momentos, que utiliza algumas categorias da Lingüistica Sistêmico-Funcional, proposta por Halliday, como apoio para as análises, assim como não se acanharia em utilizar outras metodologias para tal serviço (categorias da Pragmática, Análise da Conversação, etc.), pois, segundo Fairclough, a ADC é um método que pode se apropriar de outros métodos, residindo aí, a transdisciplinaridade, que já vem sendo debatida em outras obras.

Acerca de categorias analíticas, e talvez seguindo o tom do que se apresentou acerca da imbricação de texto com gênero/discurso/estilo, Fairclough ressalta que, ao assumir que o nosso conhecimento é parcial e incompleto, como tem sugerido, e se assumirmos que estamos constantemente buscando ampliar e aperfeiçoar esse conhecimento, então devemos aceitar que nossas categorias não são definitivas, estando abertas à mudança, o que, acredito, está muito ligado à idéia de fluidez, como visto anteriormente. Contudo, ressalta que lançar mão somente da análise textual é limitador, pois isso jamais nos permitiria enxergar a forma como os sentidos são produzidos no texto, os efeitos causais desses sentidos e o matiz ideológico ali presentes (p. 15). Desse modo, depreende-se que é só por meio do que se poderia chamar de micro e de macroanálise que se poderia realmente ler um texto criticamente. 
O autor apresenta um manifesto, na conclusão, dizendo que o livro aborda justamente uma pequena parte do que ele vê como um grande projeto, isto é, a $\mathrm{ADC}$ como uma forma de pesquisa social crítica. E ressalta que a pesquisa social realmente crítica deve se preocupar com questões sociais, fazendo com que o/a pesquisador/a se pergunte, por exemplo, como é possível que as sociedades, ao mesmo tempo em que propiciam a riqueza, permitam que haja tantas pessoas em estado de miséria absoluta. $\mathrm{Ou}$, em outros termos, o que poderia ser feito para melhorar a qualidade de vida das pessoas. Acrescenta que focalizar a língua e o discurso numa pesquisa que trata do 'novo capitalismo' é de fundamental importância, pois onde houver mudanças que transformem a vida social, então essas mudanças inevitavelmente estarão transformando a língua, pois ela é um elemento da vida social e que está dialeticamente conectado a outros.

Observando de forma geral alguns aspectos da obra, acredito que, antes de uma primeira leitura completa do livro, o/a leitor/a devesse fazer uma leitura do capítulo final, em que o autor traz o Manifesto referido e também analisa um texto com muitas das categorias apresentadas no decorrer da obra. É ao final que se encontra também o excelente glossário com os termos-chave que foram utilizados na obra, o que, aliás, conta muitos pontos para a didática do autor. É ao final ainda que se encontram os 15 textos que serão analisados no decorrer do livro e que precisam ser lidos antes da leitura teórica, pois a todo momento o autor fará referência a esses textos. Desse modo, começar o livro pelo 'final' será um ótima maneira de 'começá-lo'.

$\mathrm{O}$ autor apresenta muitos quadros-resumo no começo de cada capítulo, no desenvolvimento e também ao final desses capítulos, o que também representa todo um cuidado com a compreensão da teoria pelo/a leitor/a. Essa é uma inovação em relação aos livros anteriores do autor, os quais, sem esse recurso, tornam um pouco mais árdua a compreensão do arcabouço. Como o livro trata de muitas categorias analíticas, o autor teve o cuidado de, nos quadros iniciais de cada capítulo, fazer uma separação temática. Assim, separa questões de análise de texto de questões de análise social, em todos os quadros apresentados nos capítulos do livro, o que ajuda a organizar as idéias na cabeça do(a) leitor(a). 
Também cabe destacar a forma como o autor ilustrou todas as categorias analíticas apresentadas, analisando os 15 textos que estão no Apêndice de Textos. A dinâmica funciona muito bem no decorrer da leitura. Essa estratégia transcorre tão bem que, por exemplo, na página 132, o autor, ao explicar o processo de nominalização, pede que contrastemos 'o texto 12 com o texto 4' para melhor compreendermos como a categoria ali demonstrada foi utilizada, na prática. É bem verdade que nem todos os textos que foram usados para exemplificar as categorias estão ao final, como é o caso do horóscopo utilizado na página 58, ou o anúncio da página 136. Entretanto, isso não compromete em nada a dinâmica ali estabelecida. Muito pelo contrário. Até ajuda a diversificar os tipos de exemplos utilizados. Assim, ainda falando dos textos-exemplo, vale ressaltar a unidade temática - o 'novo capitalismo' - e a atualidade dos mesmos, assim como a sintonia desses com o teor do Manifesto, que, como vimos, traz uma profunda inquietação com causas sociais. Esse cuidado com a unidade temática dos exemplos e a proposta do livro só vêm a enriquecer o/a pesquisador/a interessado/a no estudo da ADC.

Observei, ainda, em raros momentos, que houve pequenos 'escorregões' ${ }^{1}$ na revisão do texto. Embora isso não comprometa em nada a contribuição teórica que o livro traz, tampouco atrapalhe na compreensão do texto, é importante observá-los, pois, como já havia dito, esse trabalho é uma leitura ampla de toda a obra.

\footnotetext{
${ }^{1}$ 1) ortografia: páginas 16 (texual/textual), 183 (aestheticiaztion/aestheticization); 2) repetição da palavra 'they' na página $139 ; 3)$ na pág. 2 e na pág. 234, faz referência a páginas que não estão marcadas no texto; 4) observar, ainda, se a repetição da página 184 também acontece no original, ou se foi somente na reprodução.
} 